Historic, Archive Document

Do not assume content reflects current scientific knowledge, policies, or practices. 

U. S. DEPT. OF ReARULLTURE

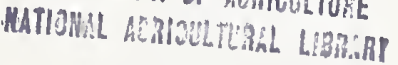

OCT 121970

CURREII SERIAL RECORDS

\section{A TRAP WITH SEX ATTRACTANT FOR MONITORING TIME OF CODLING MOTH FLIGHTS}




$$
\text { - }
$$




\title{
A TRAP WITH SEX ATTRACTANT FOR MONITORING TIME OF CODLING MOTH FLIGHTS
}

\author{
By L. G. Schoenleber, B. A. Butt, and D. O. Hathaway ${ }^{1}$
}

To obtain effective control of the codling moth (Carpocapsa pomonella (L.)) with chemical or biological measures, the native populations and flight habits of this moth must be known. lnsect traps with attractants are being used with limited success as research tools for trapping codling moths. ${ }^{2} 3$

The trap described in this report was designcd to determine the intensity and time of flight and the population trends of the codling moth (fig. 1).

\section{DESIGN AND OPERATION OF TRAP}

This insect trap was designed to capture male codling moths and to provide a composite catch at hourly intervals separately from other time periods. 1t makes 24 composite catches, then continues to recycle. This permits capturing codling moths for more than 1 day with the same intervals of hourly catch for succeeding days in the same composite sample. Insects captured during other periods can be used by changing gears in the timing mechanism. The trap includes its own power system and operates on a 12-volt battery. It also operates with a low power requirement to extend the time between battery charges. Virgin female codling moths are kept in a small screen cage to attract wild male moths. Transparent doors and crank for moving the belt permit easy access to service the trap and observe its performance.

The trap utilizes a 4-inch-wide two-ply polyester belt, which has a sticky material spread uniformly on the surface. This material, or Stickem Special, ${ }^{4}$ is a mixture of polymerized 1-butane 14 percent, 1-butene 48 percent, 2-methylpropene 35 percent, and paraffin wax 3 percent.

The trap belt with plastic cover removed provides the needed flexibility. It is enclosed by two transparent doors and sheet-metal covers except a 4 - by 6 -inch-wide

\footnotetext{
${ }^{1}$ Agricultural engineer, Agricultural Engineering Research Division, and entomologists, Entomology Research Division, respectively, Agricultural Research Service, U.S. Department of Agriculture, Yakima, Wash.

${ }^{2}$ Batiste, William C. A timing sex pheromone trap with special reference to codling moth collections. [Unpublished.]

${ }^{3}$ Butt, B. A., and Hathaway, D. O. Female sex pheromone as attractant for male codling moths. Jour. Econ. Ent. 59: 476-477. 1966.

${ }^{4}$ Mention of a proprietary product in this report does not constitute a guarantee or warranty by the U.S. Department of Agriculture over other products not mentioned.
}

area at the top. Above the exposed belt is an open-ended hood. An attractant is placed inside the hood near the top and center to attract the moths. Moths fly inside the hood to the attractant and onto the sticky belt where they are unable to free themselves.

A timing mechanism operated by a 12 -volt battery moves the belt once each hour to expose a new belt area (figs. 2 and 3). Six seconds are required to move the belt to a new position.

Covers to protect the electrical components and drive pulleys from the weather are designed for quick removal.

The electrical and mechanical components are diagramed in figure 4. A 12-volt d.c.-regulated clock (F) is connected mechanically as an integral unit with a repeat cycle cam and microswitch (G). This microswitch is wired to operate a delay relay $(\underline{H})$. Relay $(\underline{H})$ when energized closes its internal switch instantly. It then opens the circuit automatically at a preset time. The relay is connected in series with switch $(\underline{1})$, fuse $(\mathrm{J})$, battery $(\underline{\mathrm{K}})$, and motor $(\mathrm{C})$. Motor $(\mathrm{C})$ starts when relay (ㅍ) is energized.

The drive system connected to motor $(\mathrm{C})$ rotates cam (D) and moves belt (B) through linkage (A). As can: (D) rotates, microswitch (E) is closed to make a complete circuit for drive motor $(\underline{C})$. While cam $(\underline{D})$ rotates, relay (H) becomes deenergized to open its contact points. One complete revolution of cam (D) results in microswitch (E) opening the circuit to stop motor (C). Since the minimum on-time of cam and microswitch $(\underline{G})$ is 3 to 4 minutes, delay relay $(\underline{H})$ is needed (1) to shorten the period to only a few seconds for proper movement of the belt and (2) to use a minimum amount of power.

The trap includes driving arm (A), which is linked mechanically to a one-direction drive roller clutch. The 


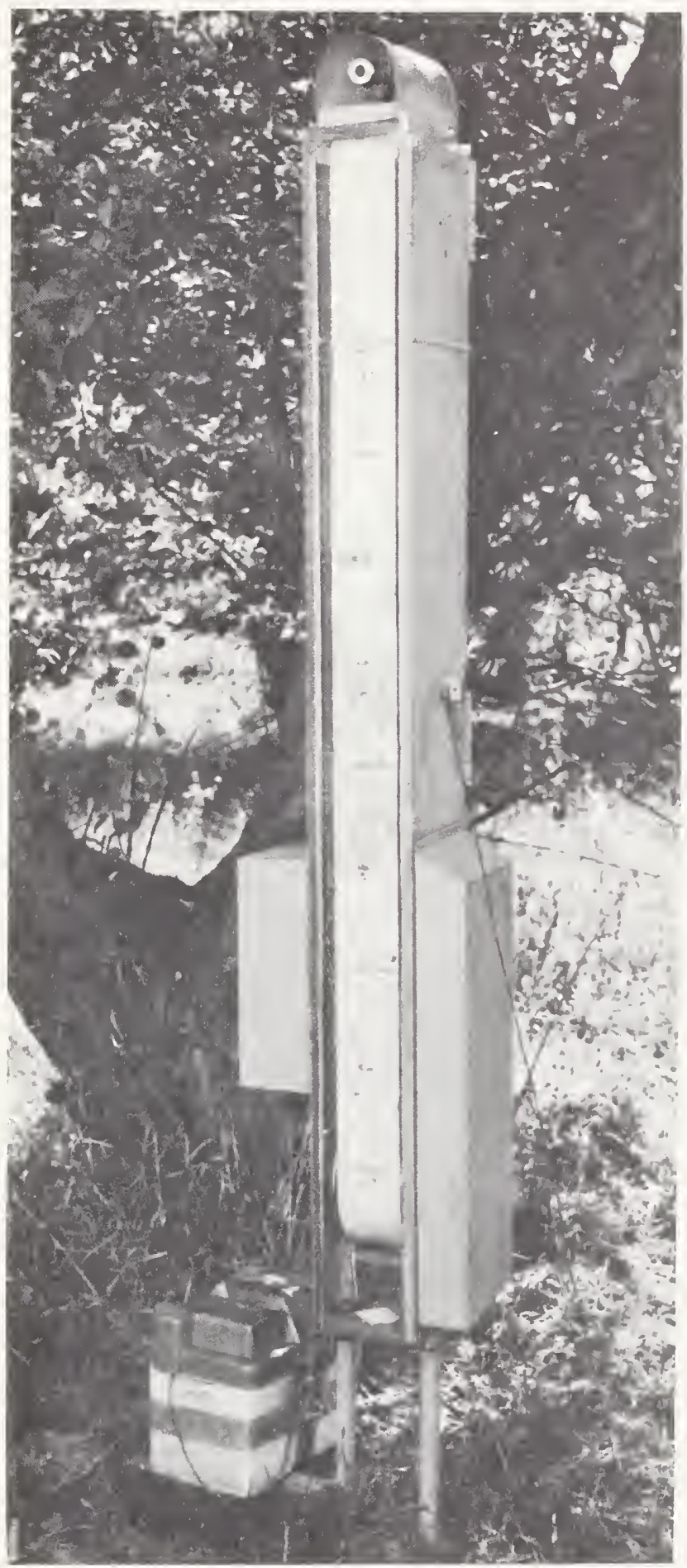

Figure 1.-Insect trap as used in orchards.

clutch is fastened to a belt drive pulley shaft. One cycle of driving arm (A) moves the belt one twenty-fourth its length when properly adjusted on the roller-clutch linkage arm. A crank fastened to the shaft is used to override the clutch for easy turning of the belt when

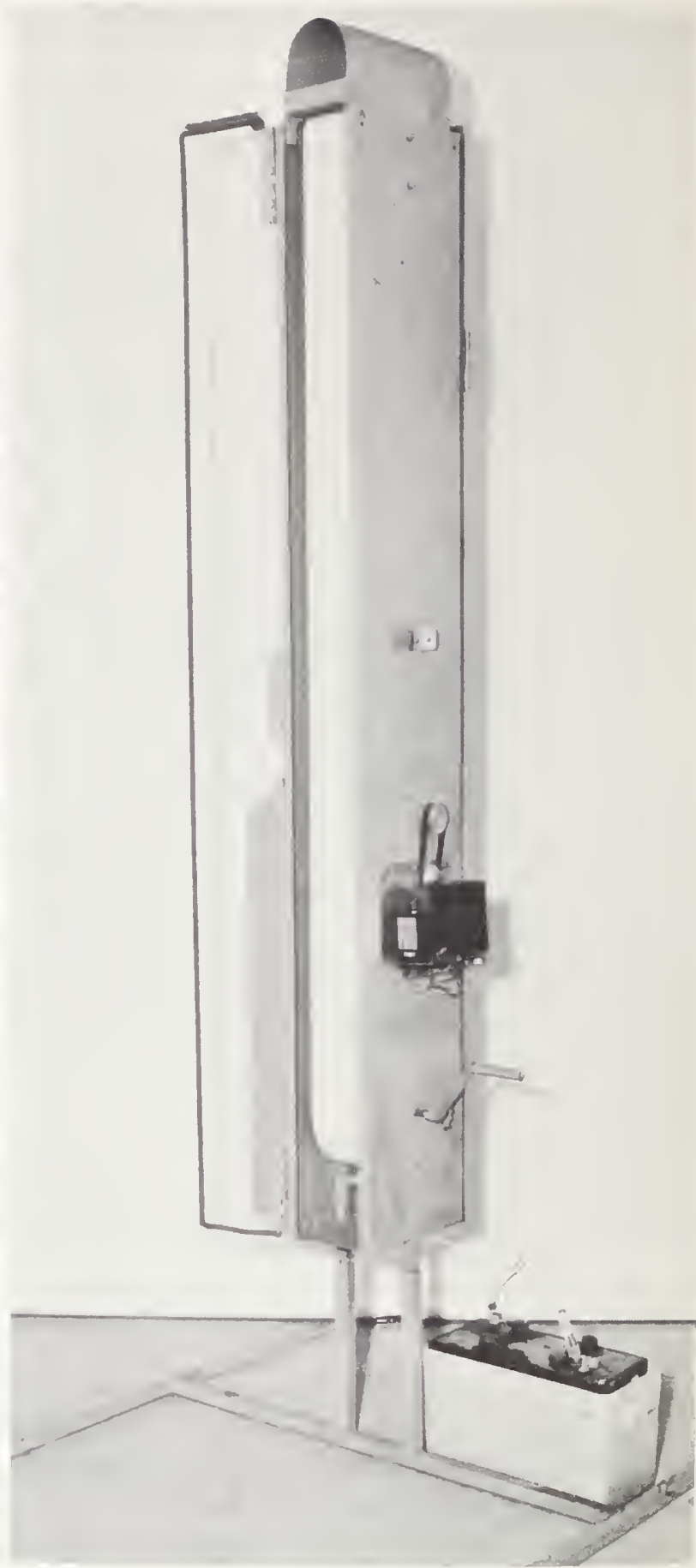

Figure 2.-Insect trap with transparent door open, showing electrical components. removing insects and resetting to expose the correct belt area.

The current required to operate the timer is 50 milliamperes. While the motor is running, a peak current of 800 milliamperes is required by the electrical system 


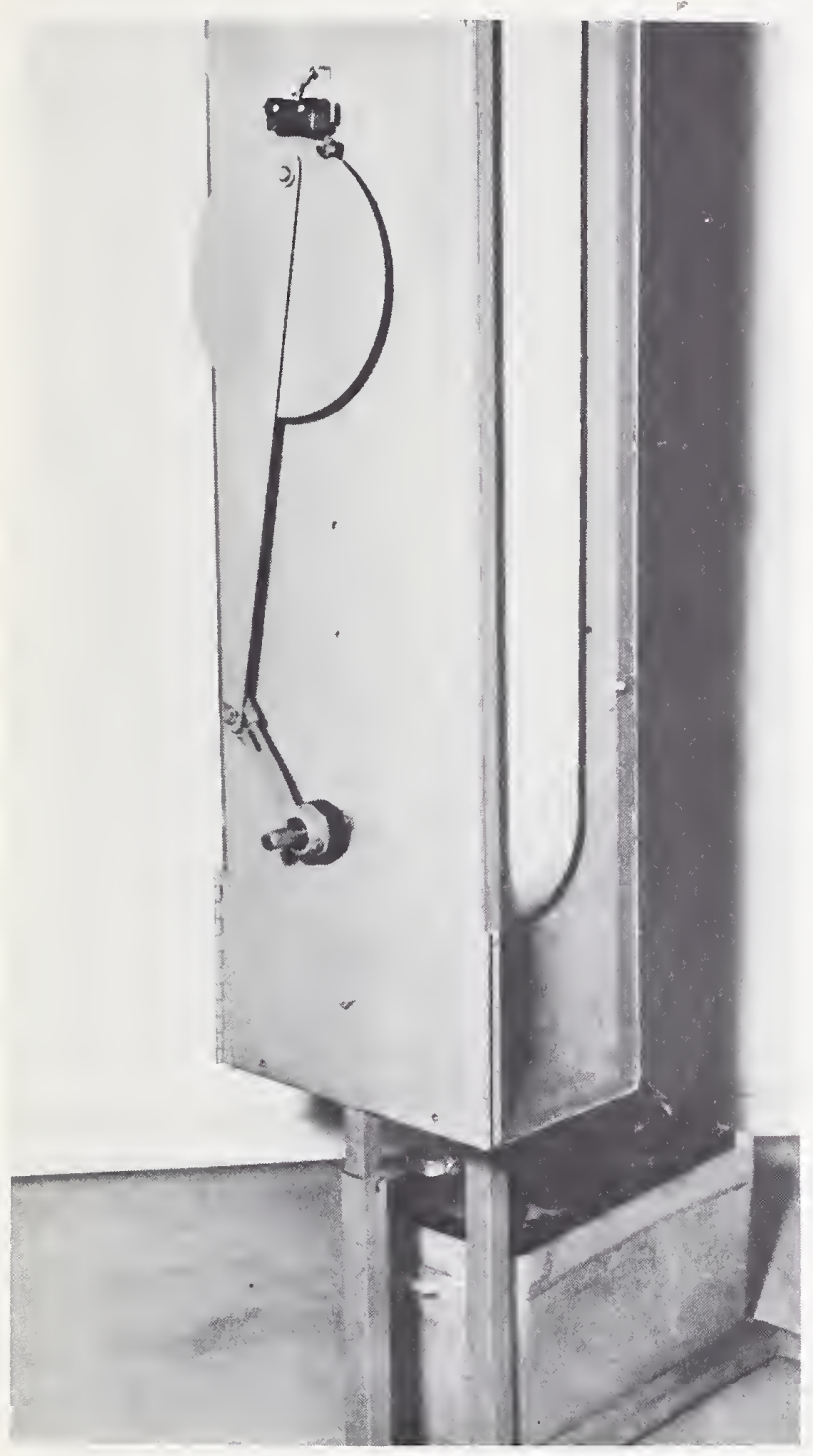

Figure 3.-Insect trap with cover removed, showing linkage drive components.

for about 3 seconds. The peak current load occurs when the belt speed is maximum. Motor (C), which moves the belt, is set to operate 6 seconds out of each hour.

General arrangement of components for the insect trap with the cover removed is shown in figure 5 . The trap is $7 \frac{1}{2}$ feet high. The drive system is shown in figure 6.

The 4-inch-wide belt runs over pulleys $(\underline{\mathrm{A}}),(\underline{\mathrm{C}})$, and (P). Each pulley has a slight crown at the center to maintain proper belt alinement. Pulley $(\underline{P})$ includes a lagging surface to afford a positive grip in moving the belt. An adjustment to keep the belt tight is provided by bolts $(E)$ and screws $(\underline{F})$ to move frame $(B)$. Adjustment (D) connected to (C) is used to make the belt run true.
Motor $(\underline{L})$ of the drive system contains a 1,280 to 1 ratio planetary gear reduction and produces 700 ounce-inches torque at 11,000 r.p.m. with 12-volt d.c. power. Pulley (M) is connected by a belt to pulley (N). Pulley $(\underline{N})$ is attached to shaft $(\underline{0})$ to drive pulley $(\underline{P})$ through linkage system (I), (J), and (K). Link arm (H) is also used as a cam to actuate microswitch $(\underline{G})$. Link arm $(\underline{K})$ includes an adjustment $(\mathrm{J})$ to make the correct belt movement. The overriding clutch is attached to link $\operatorname{arm}(\underline{\mathrm{K}})$ and the shaft driving pulley ( $\underline{\mathrm{P}})$. Crank $(\underline{Q})$ is provided to move the belt for servicing without disturbing the motor drive systim.

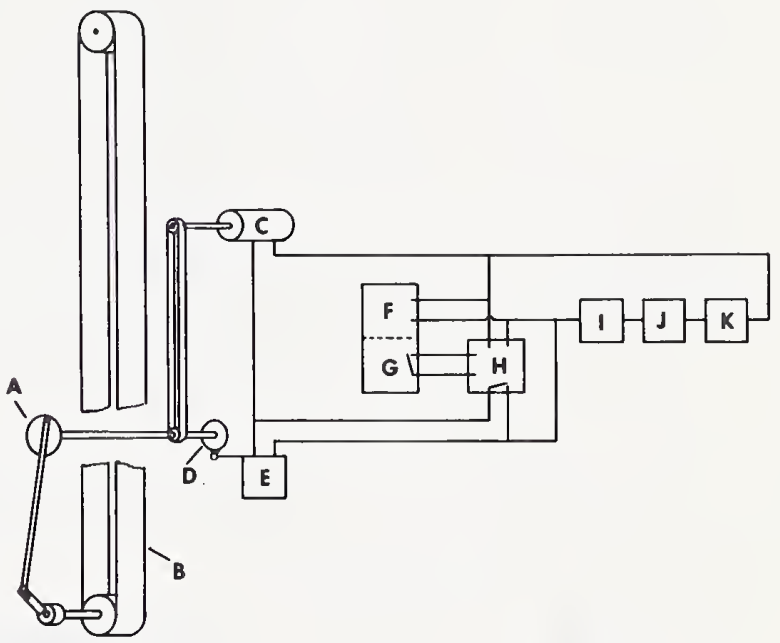

Figure 4.--Electromechanical insect trap with belt. (For identification of parts, see text.)
SIDE VIEW

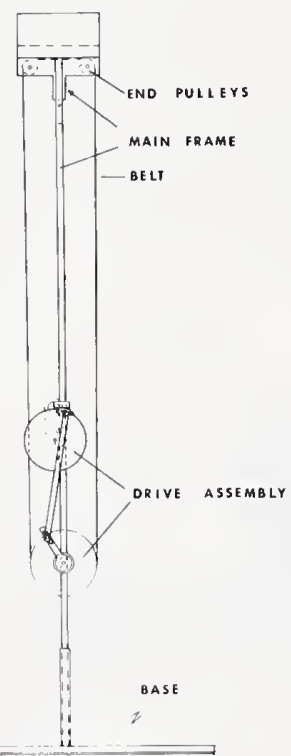

FRONT VIEW

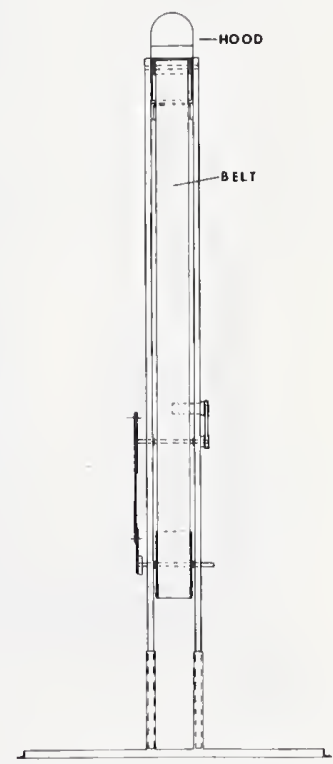

Figure 5.-Assembled insect trap. 


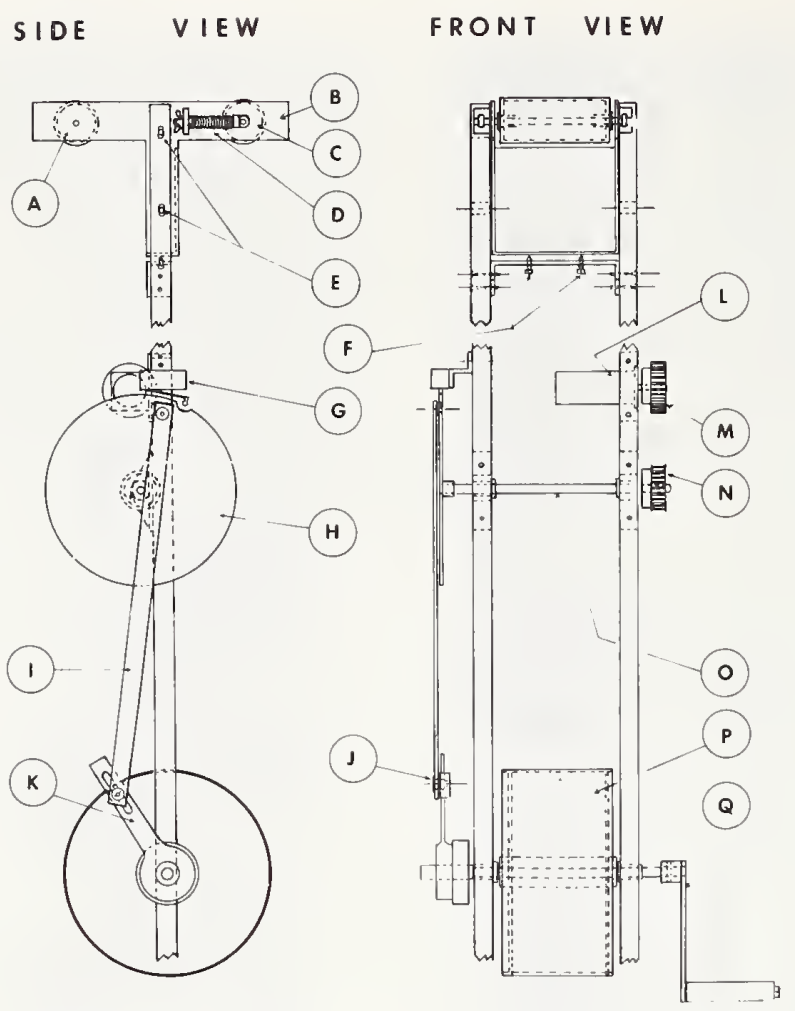

Figure 6.-Drive assembly of insect trap. (For identification of parts, see text.)

\section{USE AND PERFORMANCE OF TRAP}

The trap was operated continuously in an abandoned orchard (fig. 1) from May 13 to September 30, 1969. Ten live female moths werc kept in the screen cage located in a wire basket inside the hood of the trap above the exposed part of the belt to at tract the male moths. Penciled lines across the belt divided it into 24 equal areas, which were identified by clock hours. With this feature the belt was easily timed for catch by exposing the proper area, which indicated the hour that insects were caught. The trap was inoperative only a few times when the battery was insufficiently charged and when the caged attractant motlis werc dead.

The 12-volt battery operated up to 3 weeks before it required recharging.

Insects captured on the sticky material of the belt werc removed with tweezers. The sticky material was replaced only once on the belt areas of highest insect catch during the trapping season.

\section{NUMBERS OF CODLING MOTHS CAUGHT}

The time and numbers of moths trapped are shown in figures 7 and 8 . The solid line in figure 7 represents the time of sunset and the dotted line the time of sunrise, Pacific daylight time, based on Nautical Almanac Office, U.S. Naval Observatory. Over 730 insects were trapped during the summer. The trap was not always serviced each day. The accumulated catch by hours for these days is shown when the insects were counted. The relative numbers of codling moths trapped hourly during a 24-hour period for $4 \frac{1}{2}$ months are shown in figure 8 .
Sunset occurred between 1844 and 2059 and sunrise between 0508 and 0859 , Pacific daylight time, during this period. The peak catches were near sunset, but a large number continued to be trapped until 0100 . During the remaining hours a few insects were trapped every hour except 3 hours.

During the peak periods of insect flight in July and August (fig. 9), a maximum of 33 codling moths was trapped in 1 hour. 


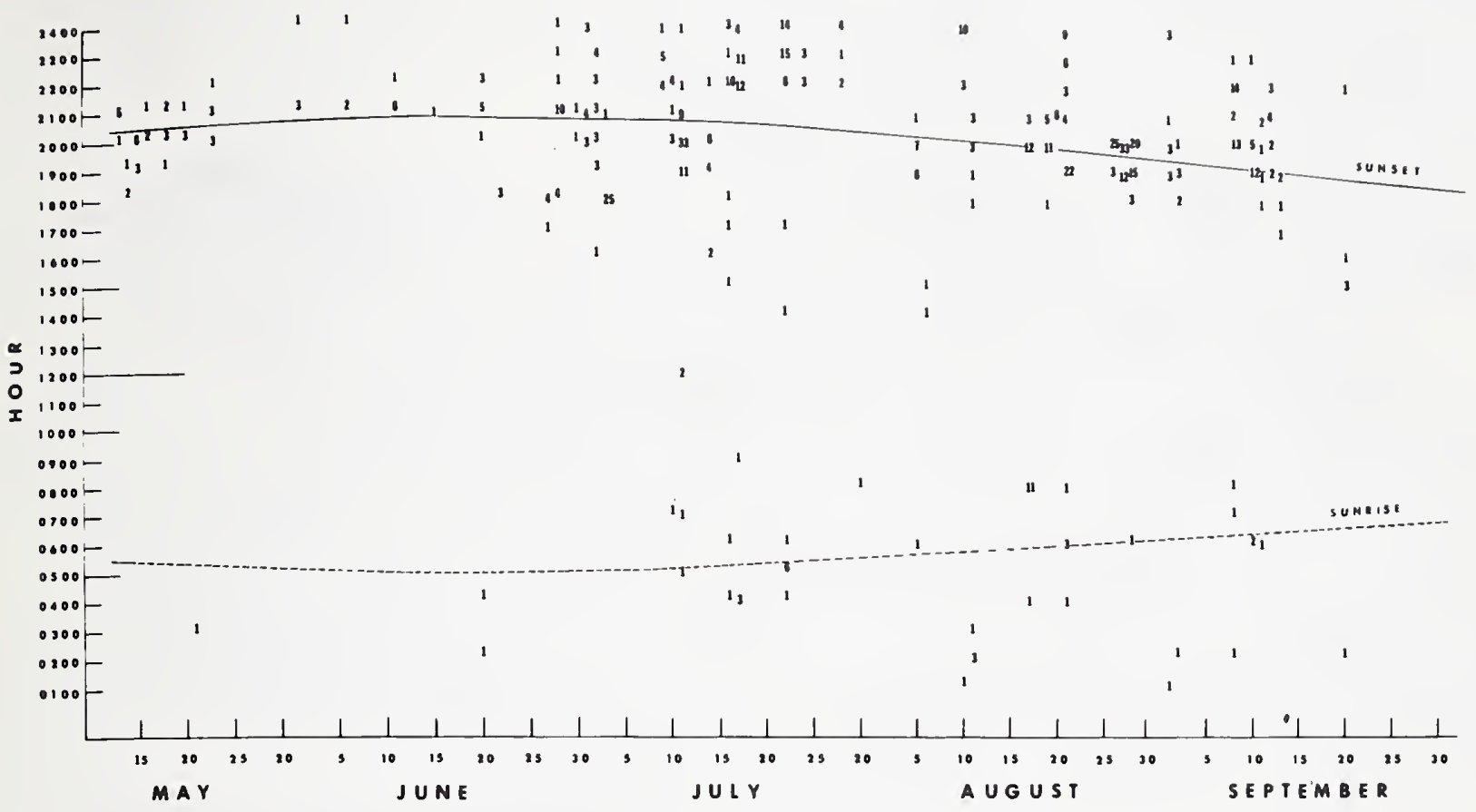

Figure 7.-Distribution of moths trapped by hour and by date from May 13 to September 30, 1969.
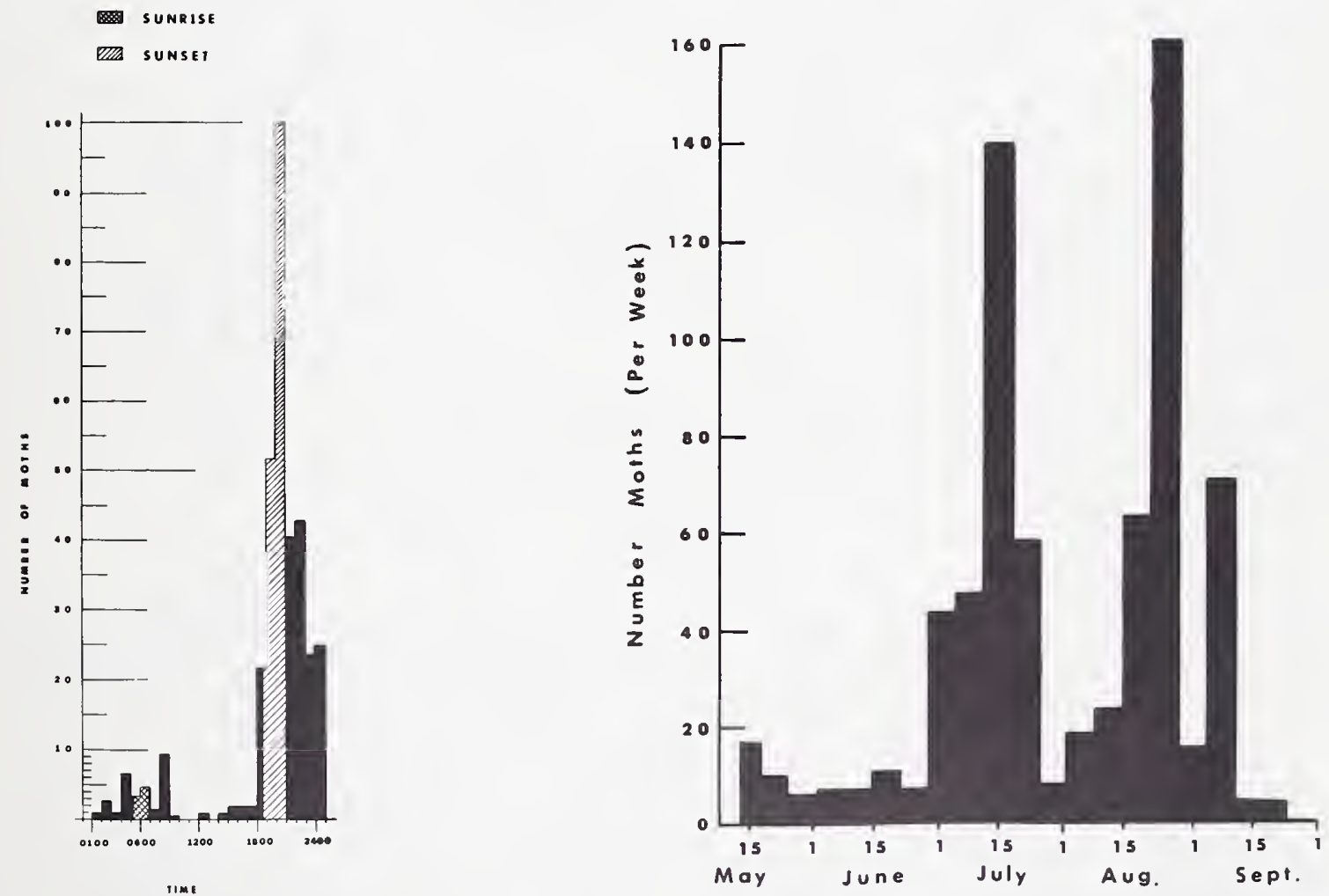

Figure 8.-Total relative distribution of moths trapped by hours from May 13 to September 30, 1969.
Figure 9.-Number of moths trapped per week from May 13 to September 30, 1969. 
UNITED STATES DEPARTMENT OF AGRICULTURE Agricultural Research Service

Beltsville, Maryland 20705

official Business

Penalty for Private Use, $\$ 300$

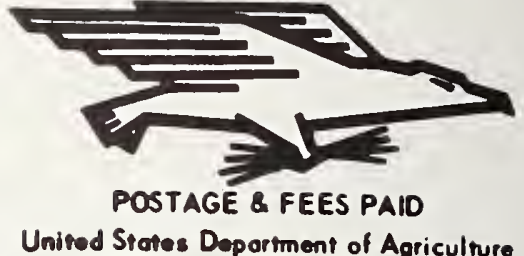

Unired States Deportment of Agriculture 